\title{
Expert Perspective on the American Diabetes Association Dietary Guidelines for Patients with Diabetes
}

\author{
An Expert Interview with Claude K Lardinois
}

University of Nevada School of Medicine, Reno, NV, US

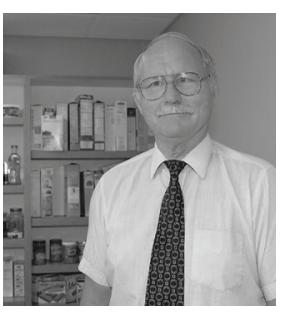

\section{Claude $\mathrm{K}$ Lardinois}

Dr Lardinois is Emeritus Professor of Medicine in the Division of Endocrinology at the University of Nevada School of Medicine, Reno. He is the Medical Director of Disease Management for the American Health Care in Rocklin, CA. His research interests include work in nutrition, diabetes, hypertension, and dyslipidemia. He has a special interest in eradicating heart disease, the major cause of death in patients with type 2 diabetes. Dr Lardinois is a Fellow of the American College of Physicians (FACP), a Master of the American College of Nutrition (MACN), and a Fellow of the American College of Endocrinology (FACE). He is board certified in internal medicine, endocrinology, and metabolism.

DOI: https://doi.org/10.17925/USE.2018.14.1.13

\section{Keywords}

American Diabetes Association Dietary Guidelines, nutrition, diabetes prevention, management, APOE, sugar

Disclosure: Claude K Lardinois has nothing to disclose in relation to this article.

Review Process: This is an expert interview and as such, has not undergone the journal's standard peer review process.

Acknowledgments: Medical writing assistance was provided by Katrina Mountfort at Touch Medical Media. Authorship: The named author meets the criteria of the International Committee of Medical Journal Editors for authorship for this manuscript, takes responsibility for the integrity of the work as a whole and has given final approval for the version to be published.

open Access: This article is published under the Creative Commons Attribution Noncommercial License, which permits any non-commercial use, distribution, adaptation and reproduction provided the original author and source are given appropriate credit. (C) The Author 2018.

Received: April 4, 2018

Published Online: April 27, 2018

Citation: US Endocrinology, 2018;14(1):13-15

Corresponding Author: Claude K Lardinois, Department of Medicine, 1700 Aquila Avenue, Reno, NV 89509-3101 US. E: lardinois@sbcglobal.net Linkedın: http://linkedin.com/in/claude-klardinois-md-facp-macn-face-11204217

Support: No external funding was received in the publication of this article.
$\mathrm{N}$ early half of American adults have prediabetes or diabetes, and more than 30 million adults and children have diabetes. ${ }^{1}$ Optimum nutrition is important in preventing diabetes, managing existing diabetes, and preventing the development of diabetes complications. The American Diabetes Association (ADA) therefore provides dietary guidelines in its "Standards of Medical Care in Diabetes". ${ }^{2}$

Dr Claude K Lardinois, MD, FACP, MACN, FACE has been an endocrinologist in Reno, NV for more than 30 years. He is an emeritus professor of endocrinology at the University of Nevada School of Medicine, and Medical Director of Disease Management for American Health Care in Rocklin, CA. His research interests include work in nutrition, diabetes, hypertension, and dyslipidemia. In an expert interview, Dr Lardinois gives his perspective on the current ADA nutrition recommendations.

\section{Q. What is your opinion on the major recommendations of the current ADA guidelines for type 2 diabetes prevention?}

The key recommendations are as follows:

a) consume less than $10 \%$ of your calories per day from added sugars;

b) consume less than $10 \%$ of your calories per day from saturated fats;

c) consume less than 2,300 mg per day of sodium; and

d) if alcohol is consumed, it should be done so in moderation, i.e., one drink per day for women and two for men.

I agree with the recommendations on sugar; the major culprits behind the diabetes epidemic are high-sugar snacks such as high fruit cereals, food containing high fructose corn syrup (HFCS), and power drinks. A diet high in fructose rather than glucose has a negative effect on metabolism, which is why people can gain weight quickly after consuming high fructose containing products.

The recommendations in the US have advised people reduce fat and replace it with carbohydrate, but this is based solely on the Seven Countries study by Ancel Keys. ${ }^{3}$ While this advice intended that people increase their intake of fruit and vegetables, instead people have increased their intake of HFCS. To this date there has not been a single clinical study that has conclusively proven that a diet high in saturated fats increases the risk of cardiovascular disease (CVD). ${ }^{4}$ It is time to change this recommendation; 
evidence shows that the Masai people of East Africa consume a high proportion of their calories from saturated fat but have a very low risk of CVD. ${ }^{5}$ The notion that saturated fat is bad for people with diabetes is wrong and should be abandoned. Among new fashionable diets, the Atkins diet, which is high in fat, has been the most successful in lowering blood pressure and weight when compared to diets like Zone, Lifestyle, Exercise, Attitudes, Relationships, and Nutrition (LEARN) and Ornish.

In order to study the question of saturated fats conclusively, we need a population of compliant individuals. The Minnesota Coronary Survey began in 1968 and was conducted in six Minnesota state mental hospitals and one nursing home. It involved 4,393 institutionalized men and 4,664 institutionalized women. The trial compared the effects of a diet with $18 \%$ saturated fat and one with $9 \%$ saturated fat. The investigators were surprised to find that there was no difference between the groups in terms of CVD events and mortality. These data were not published until 1989 because the authors were disappointed in the way the results turned out. ${ }^{6}$ Rumors abound because Ancel Keys was working in Minnesota at the time.

I do recommend people should reduce the amount of red meat in their diet. Red meat contains choline, which the gut bacteria can convert to trimethylamine (TMA). The latter can be further oxidized by the liver to produce TMA N-oxide (TMAO). High levels of TMAO have been associated with increased atherosclerosis.7 However, fish and seafood contain considerable amounts of TMAO and are generally accepted as cardioprotective: a puzzling paradox. ${ }^{8}$ While I still recommend people reduce red meat in their diet, the TMAO story may be a red herring.

In terms of the recommendation on salt, there is a belief that sodium raises blood pressure and that we need to reduce it to reduce CVD. However, there is evidence that heavily restricting salt in the diet increases mortality. ${ }^{9}$ If a person with type 2 diabetes has hypertension that is not well controlled, reduced sodium might be indicated. Rising consumption of fructose has been matched with growing rates of hypertension..$^{10}$ This begs the question, "are we looking at the wrong white crystal?" when it comes to addressing blood pressure.

There is no question that modest alcohol consumption is associated with reduction in CVD for the vast majority of the population, ${ }^{11}$ but it is important to know your apolipoprotein (APOE) genotype. APOE is a genetic marker of which there are three types: APOE E2, APOE E3 and APOE E4. The most common combination, seen in around $60 \%$ of the population is E3/E3. However, $25 \%$ of the population carry one or two copies of the E4 allele. In these patients, alcohol can lead to worsening lipid profiles. ${ }^{12}$ In these patients, I recommend the consumption of only one alcoholic drink per week because triglyceride levels can be very sensitive to alcohol in this group. A low-fat diet (20\% energy consumption from fat) with 25-30\% protein is also very effective in this group in reducing low-density lipoprotein cholesterol (LDL-C) often better than a statin.

I recommend a personalized approach to nutrition.

\section{Q. How has nutrition guidance changed for the prevention and management of type 2 diabetes?}

The link between obesity and diabetes is well established, and the guidelines have increasingly focused on weight management. It is important to remember that many people with diabetes are not obese; among individuals with insulin resistant diabetes, there are more non-obese people than obese. ${ }^{13}$ There has been an increased focus on exercise following reports of the health benefits of exercise for 30 minutes a day. ${ }^{14}$

However, if we do not change our nutritional recommendations based on science, the diabetes epidemic will regrettably continue. Firstly, we have to get away from the mindset that saturated fats are bad. Current scientific evidence does not clearly support cardiovascular guidelines that encourage higher consumption of polyunsaturated fatty acids and lower consumption of total saturated fats. Secondly, more attention must be focused on how increasing consumption of fructose impacts adversely on diabetes and hypertension. So far, the only white crystal that gets incorporated into guidelines is salt.

\section{Q. How do you help your patients understand the importance of nutrition in diabetes?}

I tell my patients: 'more foot and less fork'. I advise them to reduce calories if they are overweight, and tell them specific things to avoid, in particular sugar-containing drinks especially those containing HFCS, as well as red meat. In addition, I encourage people to quit smoking as this increases insulin resistance. ${ }^{15}$ I also stress the importance of an exercise program. If I can persuade patients to exercise for 30 minutes a day, I consider this a major achievement; however, this is closer to weight maintenance. To reduce weight, 90-120 minutes 7 days a week is necessary but this is not possible for many patients. Working with a certified diabetes education nurse and/or dietician helps motivate some patients to take more ownership of their diabetes. I also encourage my patients to have a test to determine their APOE genotype, although insurance companies do not cover this. Dieticians are increasingly recognizing the importance of knowing the patient's APOE in deciding the right combination of energy from carbohydrates, proteins, and fat as well as alcohol.

\section{Q. What other changes would you like to make to the guidelines for type 2 diabetes?}

Appreciate that the goal for glycated hemoglobin (A1C) must be based on age and duration of diabetes.

In 1988, a group of health care providers including myself got together to implement diabetes guidelines for the Veterans Affair Medical Center (VAMC). During the previous 2 years there was an aggressive attempt to get as many veterans to an A1c of $7 \%$ as recommended by the ADA. Many veterans suffered severe hypoglycemia as a consequence of this "one-size" fits all A1c mentality. What we quickly appreciated was older patients and patients with diabetes complications (defined as retinopathy, nephropathy or neuropathy) had the highest risk of experiencing severe hypoglycemia. Based on these findings, the VAMC recommended that patients under 75 with no complications of diabetes diligently work to get their A1c to $7 \%$. However, patients under 75 with established complications, the goal for A1c should be $8 \%$ to minimize the risk of severe hypoglycemia. That same A1c goal of $8 \%$ was recommended for all patients over the age of 75 and up to $9 \%$ was considered acceptable for patients over 75 with established complications. These recommendations were presented at the ADA in 1988 and were not well received. However, over time the VAMC guidelines have become more accepted. $\square$ 
1. Centers for Disease Control and Prevention. New CDC report: More than 100 million Americans have diabetes or prediabetes. 2017. Available at: www.cdc.gov/media/ releases/2017/p0718-diabetes-report.html (accessed March 29, 2018).

2. American Diabetes Association. 4. Lifestyle Management: Standards of Medical Care in Diabetes-2018. Diabetes Care 2018;41:S38-50.

3. Keys A, Menotti A, Karvonen MJ, et al. The diet and 15-year death rate in the seven countries study. Am J Epidemiol. 1986;124:903-15

4. Harcombe Z, Baker JS, Cooper SM, et al. Evidence from randomised controlled trials did not support the introduction of dietary fat guidelines in 1977 and 1983: a systematic review and meta-analysis. Open Heart. 2015;2:e000196. DOI: 10.1136/ openhrt-2014-000196.

5. Mann GV, Shaffer RD, Anderson RS, Sandstead HH.
Cardiovascular disease in the Masai. J Atheroscler Res. 1964;4:289-312.

6. Frantz ID Jr., Dawson EA, Ashman PL, et al. Test of effect of lipid lowering by diet on cardiovascular risk. The Minnesota Coronary Survey. Arteriosclerosis. 1989;9:129-35.

7. Koeth RA, Wang Z, Levison BS, et al. Intestinal microbiota metabolism of $\mathrm{L}$-carnitine, a nutrient in red meat, promotes atherosclerosis. Nat Med. 2013;19:576-85.

8. Landfald B, Valeur J, Berstad, A. Raa J. Microbial trimethylamine-N oxide as a disease marker: something fishy? Microb Ecol Health Dis. 2017. 28:1327309.

9. Graudal N, Jürgens G, Baslund B, Alderman MH. Compared with usual sodium intake, low- and excessive-sodium diets are associated with increased mortality: a meta-analysis. Am 」 Hypertens. 2014;27:1129-37.

10. Hines LM, Rimm EB. Moderate alcohol consumption and coronary heart disease: a review. Postgrad Med J. 2001;77:747-52.

11. Klein $A V$, Kiat $H$. The mechanisms underlying fructose-induced hypertension: a review. J Hypertens. 2015;33:912-20.

12. Marques-Vidal P, Bongard V, Ruidavets JB, et al. Obesity and alcohol modulate the effect of apolipoprotein E polymorphism on lipids and insulin. Obes Res. 2003;11:1200-6.

13. George AM, Jacob AG, Fogelfeld L. Lean diabetes mellitus: An emerging entity in the era of obesity. World I Diabetes. 2015;6:613-20.

14. McNally S. Exercise: The miracle cure and the role of the doctor in promoting it. 2015. Available at: www.aomrc.org.uk/wp-content/ uploads/2016//Exercise_the_Miracle_Cure_0215.pdf (accessed March 29, 2018)

15. Willi $C$, Bodenmann $P$, Ghali WA, et al. Active smoking and the risk of type 2 diabetes: a systematic review and meta-analysis. JAMA. 2007;298:2654-64 